\title{
General practice orthopaedic outpatient referrals in North Staffordshire
}

\author{
ALISTAIR K ROSS, WILLIAM A DAVIS, GRAEME HORN, ROSEMARY WILLIAMS
}

\begin{abstract}
A study was made of 813 orthopaedic referrals by 134 general practitioners in North Staffordshire. The referral rates showed no relation to practice list size or the doctors' previous orthopaedic experience. The published waiting times did not accurately reflect clinic vacancies, and no effective priority rating of letters by consultants was shown. Less than $1 \%$ of patients had an appointment within four weeks. One quarter of the patients failed to attend and, of those who did, $27 \%$ received physiotherapy or a "simple" appliance, or both, while $16 \%$ received treatment already available from their general practitioner. Patients from high referring doctors showed the same pattern of distribution in body area affected and treatment outcome as those from low referring doctors, but had a significantly longer time to wait for their appointment.
\end{abstract}

A survey of non-attenders showed that $56 \%$ of the patients failed to attend because the condition had resolved.

Department of Postgraduate Medicine, University of Keele, Staffordshire

ALISTAIR K ROSS, MB, CHB, FRCGP, senior lecturer in general practice

\footnotetext{
Operational Research Unit, West Midlands Regional Health Authority

WILLIAM A DAVIS, BSC, operational research officer

GRAEME HORN, BSC, operational research officer

ROSEMARY WILLIAMS, BSC, operational research officer
}

Correspondence to: $\operatorname{Dr}$ A K Ross, The Surgery, Palmerston Street, Wolstanton, Newcastle, Staffordshire.

\section{Introduction}

Orthopaedic inpatient and outpatient waiting lists have long been described as a problem in the National Health Service. It has been shown that general practitioner referral rates in all specialties vary considerably and to a degree that is not explained by differences in population morbidity. ${ }^{1}$ Studies of orthopaedic outpatient waiting lists using questionnaires sent to patients ${ }^{2}{ }^{3}$ have shown the inefficiency of the present system. In a report on orthopaedic services to the Secretary of State for Social Services ${ }^{4}$ a working party on orthopaedic waiting times commented on waiting lists: "National recommendations and blue prints for their solution may have only limited value, and that therefore places on each district the responsibility for assessing its own particular problem."

In North Staffordshire the official waiting time for adult cases to be seen by an orthopaedic surgeon in April 1980 was 24 to 53 weeks at the Hartshill Orthopaedic Hospital, where five consultants held seven clinics a week, and 19 weeks at the Haywood Hospital, where two consultants held two clinics a week. Most general practitioners in the area had no direct access to physiotherapy.

The objectives of the study were to examine orthopaedic referral patterns of general practitioners in North Staffordshire, hospital clinic booking policies, and the treatment outcome of the patients referred, in the hope that the findings might give some guidance on how the situation might be improved.

\section{Method}

A letter and questionnaire were sent to 243 referring general practitioners identified from the hospital postal lists. Those general practitioners who claimed to refer all or virtually all their orthopaedic referrals to either or both of these hospitals formed the study group. Data on the waiting list were obtained from the referral 
letters held by the hospital on 4 May 1980. These letters had a structured format inviting the referrer to give details of diagnosis, blood pressure, urine test, hazards and sensitivities, and current treatment. The patient's waiting time was calculated from the date of the letter and that of the appointment, and information on nonattendance was obtained from clinic registers and hospital case notes.

The treatment the patients received in the six months after their first attendance was also extracted from the case notes and classified in the following way: (1) no treatment: consultation only; (2) general practitioner available: only treatment that a general practitioner could have prescribed or arranged; (3) physiotherapy or appliance: physiotherapy or a simple appliance, or both. The definition of a simple appliance was agreed by AKR and a local consultant orthopaedic surgeon and included: foot arch supports; cushion/plastic insoles; heel raise/pads; cervical collar; lumbar belt; and futuro wrist splint; (4) specialist treatment: treatment that only a consultant should prescribe. This included being put on a waiting list for operation; (5) continuing episode: any of categories 1-3 where the episode was not completed.

Questionnaires were sent to the general practitioners of those patients who failed to attend their appointment at the Hartshill Orthopaedic Hospital. Information was requested on the treatment and outcome and reason for non-attendance.

\section{Results}

Of the 243 practice profile questionnaires sent, $204(84 \%)$ were completed. One hundred and thirty four doctors indicated that they referred all or virtually all their orthopaedic patients to one or other or both hospitals. They formed the study group, whose patients were examined in detail : $103(77 \%)$ were United Kingdom graduates and $27(20 \%)$ indicated that they had had previous orthopaedic hospital experience.

There were 1329 patients on the waiting list for an orthopaedic appointment on 4 May 1980, of whom $1120(84 \%)$ had been referred from general practice, and $813(61 \%)$ of them from our study group. The latter averaged $6 \cdot 1$ referrals per doctor, ranging from $0-31$ with a heavily skewed distribution (fig 1). It was decided to classify

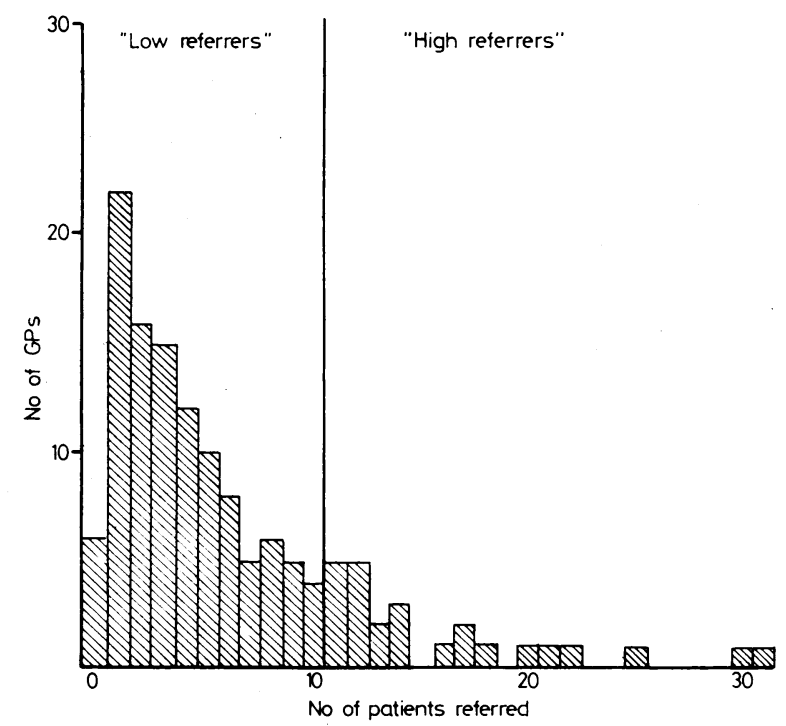

FIG 1-Number of patients referred by study group general practitioners.

arbitrarily a subgroup of "high referrers"- that is, the approximate top $20 \%$ ( 25 doctors), each of whom had referred 11 or more patients. The remaining doctors (109) were "low referrers."

No correlation was found between the referral rate and any of the doctor variables, including practice list size and previous orthopaedic experience. One third of the letters from high referring doctors were typewritten compared with $55 \%$ from the rest $(p<0.001)$. The body areas most frequently referred were: back $(24 \%)$, knee $(17 \%)$, foot $(17 \%)$, and shoulder $(9 \%)$, and the distribution was similar in the two groups. Information on the patients' blood pressure, urine tests, and hazards and sensitivities was given in less than $5 \%$ of cases. In only six letters $(0.7 \%)$ was any indication of urgency made by the referring doctor: $0.9 \%$ of all patients were given an appointment within four weeks, and 3.3\% within eight weeks. Of the 813 patients $608(75 \%)$ attended for their appointment. The case notes of 528 of these patients were found and their treatment data extracted. Table I shows that just over a third of patients received specialist treatment, while $43 \%$ received treatment already available to their general practitioner, or a simple appliance or physiotherapy, or both. The

TABLE I-Treatment outcome (within six months)

\begin{tabular}{lcc}
\hline \multicolumn{1}{c}{ Treatment } & Absolute frequency & Relative frequency (", $)$ \\
\hline No treatment & 65 & 12.3 \\
General practitioner available & 86 & $16 \cdot 3$ \\
Physiotherapy/appliance & 140 & 26.5 \\
Specialist treatment & 178 & 33.7 \\
Continuing episode & 59 & $11 \cdot 2$ \\
\hline Total & 528 & 100 \\
\hline
\end{tabular}

expectation that patients allocated a shorter waiting time would show a higher proportion of "specialist" treatment was not confirmed when treatment outcome was cross tabulated with waiting time (table II). Similar results were found in using eight and 13 week thresholds. No important difference in pattern of treatment was found between patients from high referring and those from low referring doctors, though the former had to wait appreciably longer for their appointment (table III).

TABLE II-Treatment outcome by waiting time for appointment

\begin{tabular}{|c|c|c|c|c|c|}
\hline \multirow[b]{2}{*}{ Treatment } & \multicolumn{4}{|c|}{ Waiting time } & \multirow{2}{*}{$\begin{array}{l}\text { Total } \\
\text { No }\end{array}$} \\
\hline & $\begin{array}{l}1-17 \\
\text { No }\end{array}$ & 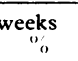 & $\mathrm{No}^{17}$ & weeks & \\
\hline $\begin{array}{l}\text { No treatment } \\
\text { General practitioner available } \\
\text { Physiotherapy, appliance } \\
\text { Specialist treatment } \\
\text { Continuing episode }\end{array}$ & $\begin{array}{l}27 \\
27 \\
44 \\
55 \\
17\end{array}$ & $\begin{array}{l}15 \cdot 9 \\
15 \cdot 9 \\
25 \cdot 9 \\
32 \cdot 3 \\
10\end{array}$ & $\begin{array}{r}37 \\
57 \\
95 \\
114 \\
38 \\
\end{array}$ & $\begin{array}{l}10 \cdot 9 \\
16 \cdot 7 \\
27 \cdot 9 \\
33 \cdot 4 \\
11 \cdot 1\end{array}$ & $\begin{array}{r}64 \\
84 \\
139 \\
169 \\
55\end{array}$ \\
\hline Total & 170 & 100 & 341 & 100 & 511 \\
\hline
\end{tabular}

TABLE III-Type of referrer by waiting time for appointment

\begin{tabular}{|c|c|c|c|c|c|}
\hline \multirow{3}{*}{$\begin{array}{l}\text { Type of referrer } \\
\begin{array}{c}\text { High } \\
\text { Low }\end{array}\end{array}$} & \multicolumn{4}{|c|}{ Waiting time } & \multirow{3}{*}{$\begin{array}{r}\text { Total } \\
\begin{array}{l}236 \\
277\end{array}\end{array}$} \\
\hline & \multicolumn{2}{|c|}{$\begin{array}{l}1-17 \text { weeks } \\
\text { No }\end{array}$} & \multicolumn{2}{|c|}{ No $>17$ weeks } & \\
\hline & $\begin{array}{r}62 \\
108\end{array}$ & $\begin{array}{l}26 \cdot 3 \\
39 \cdot 0\end{array}$ & $\begin{array}{l}174^{*} \\
169^{\circ}\end{array}$ & $\begin{array}{l}73.7 \\
61 \cdot 0\end{array}$ & \\
\hline Total & 170 & $33 \cdot 1$ & 343 & 66.9 & 513 \\
\hline
\end{tabular}

Examination of the clinic bookings on 4 May 1980 showed an increasing number of vacancies in clinics from six weeks onwards, yet patients had been booked through until April 1981-that is, 11 months ahead. Examination of attendances at the clinics showed that from June onwards less than half the patients seen had been booked before 4 May (fig 2). The eight patients (booked in May) with appointments after January 1981 failed to attend. We assumed that these vacancies had been kept for more urgent conditions, and realised that our waiting list figures might therefore be a biased selection of the study group patients seen in the clinics. We therefoie collected information on the treatment outcome of those "extra" patients, from our study group, seen at the clinics in May-August 1980. Table IV shows that the treatment outcome in these patients did not differ greatly from that in patients already on the waiting 
list on 4 May-that is, their need for specialist treatment was no greater.

Overall, $25_{\prime}^{\prime}$ of referred patients did not attend. Questionnaires were sent to the doctors of the 180 patients who failed to attend the Hartshill Orthopaedic Hospital clinics, and $175(97 \%)$ were returned. One hundred and thirty four $(74 \%)$ were still on the list of the referring general practitioner. Of these, $34(25 \%)$ had been seen privately, and in $75(56 \%)$ the reason given for non-attendance was that the condition had resolved.

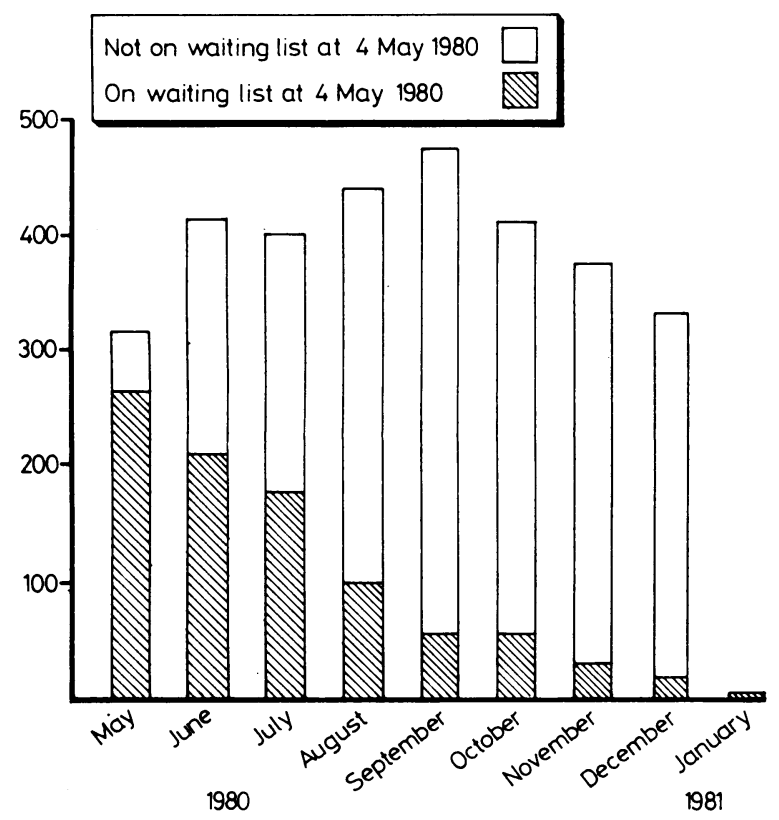

FIG 2-Total number of attendances.

TABLE IV-Treatment outcome (May to August 1980) in those patients booked before and after 4 May

\begin{tabular}{|c|c|c|c|c|c|}
\hline \multirow{2}{*}{ Treatment } & \multicolumn{2}{|c|}{$\begin{array}{c}\text { Booked before } \\
4 \text { May }\end{array}$} & \multicolumn{2}{|c|}{$\begin{array}{l}\text { Booked after } \\
4 \text { May }\end{array}$} & \multirow{2}{*}{ Total } \\
\hline & No & $\because$ & No & $"$ & \\
\hline $\begin{array}{l}\text { No treatment } \\
\text { General practitioner available } \\
\text { Physiotherapy/appliance } \\
\text { Specialist treatment } \\
\text { Continuing episode }\end{array}$ & $\begin{array}{r}51 \\
64 \\
102 \\
137 \\
32\end{array}$ & $\begin{array}{l}60 \cdot 7 \\
68 \cdot 8 \\
64 \cdot 2 \\
62 \cdot 8 \\
62 \cdot 7\end{array}$ & $\begin{array}{l}33 \\
29 \\
57 \\
81 \\
19\end{array}$ & $\begin{array}{l}39 \cdot 3 \\
31 \cdot 2 \\
38 \cdot 5 \\
37 \cdot 2 \\
37 \cdot 3\end{array}$ & $\begin{array}{r}84 \\
93 \\
159 \\
218 \\
51\end{array}$ \\
\hline Total & 386 & $63 \cdot 8$ & 219 & $36 \cdot 2$ & 605 \\
\hline
\end{tabular}

Missing values $=6$

$\chi^{2}=1 \cdot 48$ (not significant).

\section{Discussion}

Outpatient waiting lists are determined by referral habits, the organisation of the clinics, and the ratio of inpatient to outpatient activities. The wide range in referral patterns in orthopaedic medicine probably reflects each doctor's conception of his role in managing patients with chronic conditions. The appreciably lower incidence of typewritten letters in the high referring doctors suggests less "practice organisation" in this group.

The organisation of clinics is determined solely by the local consultants and hospital administrators. Klein pointed out their great power in determining what was administratively feasible and stated that whatever outpatient clinic waiting lists represented it was not consumer demand. ${ }^{5}$ The growth in the number of operations for joint prostheses and other highly technical surgical procedures now requires orthopaedic surgeons to spend longer sessions in the operating theatre and presumably a proportionally greater time with inpatients than before.
The finding in this study that some patients were booked for clinics months ahead while progressively more vacancies were available at earlier clinics was related to the consultants' practice of placing an initial limit on new patients booked in those clinics appreciably below the maximum number stated in the booking rules. This habit presumably reflected the consultants' wishes for flexibility to enable them to cope with "urgent" cases. Examination showed, however, that the study group patients subsequently allocated to these vacancies received the same treatment as those who had been waiting longer. These findings, plus the fact that only $0.9 \%$ of patients were seen within four weeks, and only $0.7 \%$ of referral letters indicated urgency, suggest that urgent conditions are mainly treated elsewhere, the waiting list consisting largely of chronic conditions that do not need a consultant's skills for their treatment.

An effective urgency rating for an appointment requires adequate information in the referral letter and many in this study were deficient in this respect-understandably, perhaps, when the waiting time for an appointment is over six months. Designing and using structured referral letters that request detailed clinical information is, on its own, unproductive. One of the most important items of information that the doctor should give is a clear indication of the real reason for referralfor example, operation, manipulation, physiotherapy, opinion, social pressures.

This study showed that a quarter of patients did not keep their appointment and suggests that more than half had defaulted because their condition had resolved. Of those who did attend, $43 \%$ received treatment already available from their general practitioner, or physiotherapy or a simple appliance, or both. These facts highlight the inefficiency of the present system. Recommendations have long been made for physiotherapy and simple orthopaedic appliances to be directly available to general practitioners, and providing such facilities may reduce hospital referral. ${ }^{14}{ }^{6}$ At the very least, it would enable many of the patients to receive their treatment much sooner than they do at present. We accept that the categories of treatment used are oversimplified. The classifications were used here in an attempt to identify qualitatively the "need for referral," and in particular those patients who might have been treated in the community if a physiotherapy service and access to some simple appliances had been available.

A better understanding is required on both sides of the factors involved in referring patients, organising clinics, and the most effective use of physiotherapy and other resources. Arrangements are being made in this district for general practitioners, consultants, and other interested parties to meet to examine and discuss these matters in the light of the findings of this study.

We thank Mr W A Lawton, statistician/systems analyst, North Staffs District Health Authority, for analysing the general practitioner and referral letter surveys; the consultants who allowed access to the patient files and clinic registers; the orthopaedic administrative staff for their cooperation and tolerance; and all the general practitioners who completed and returned the questionnaires.

\section{References}

${ }^{1}$ Forsyth G, Logan RFL. Gateway or dividing line? A study of hospital outpatients in the 1960s. London: Oxford University Press for Nuffield Provincial Hospitals Trust, 1968.

${ }^{2}$ Lourie JA. Notes on an orthopaedic waiting list. Br $\mathcal{F}$ Clin Pract 1978; $32: 224-5$.

${ }^{3}$ West RR, McKibbin B. Shortening waiting lists in orthopaedic surgery outpatient clinics. Br Med f 1982;284:728-30.

${ }^{4}$ Department of Health and Social Security. Orthopaedic services: waiting time for outpatient appointments and inpatient treatment. Report of a Working Party to the Secretary of State for Social Services. London: HMSO, 1981.

${ }^{5}$ Klein R. Reflections of an ex-AHA member. Br Med f 1982;284:992-4.

${ }^{6}$ Royal Commission on the National Health Service. Report. Cmnd 7615. London: HMSO, 1979.

(Accepted 22 fuly 1983)

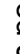

(2) 